\title{
A formação de professores na escola de Física do CERN: uma análise a partir dos focos da aprendizagem do professor pesquisador
}

\author{
Thiago Queiroz Costal \\ Instituto Federal do Paraná \\ Ivaiporã - PR \\ Sergio de Mello Arruda ${ }^{1}$ \\ Universidade Estadual de Londrina \\ Londrina - PR \\ Marinez Meneghello Passos ${ }^{1}$ \\ Universidade Estadual de Londrina \\ Londrina - PR
}

\section{Resumo}

Este artigo trata da formação continuada de professores de Física de países lusófonos, no contexto da Escola de Física do Centro Europeu de Pesquisas Nucleares (CERN), realizada em parceria com pesquisadores e instituições de Portugal. Nossas principais inspirações teóricas e metodológicas foram os Focos da Aprendizagem do Professor Pesquisador (FAPP) e a Análise de Conteúdo (AC). Embasados em tais pressupostos, nosso objetivo principal foi evidenciar indícios de aprendizagem de um professor brasileiro participante da edição do ano de 2019 desta escola de Física que se propôs a investigar elementos da própria prática no decorrer desta formação continuada, por meio do instrumento denominado Focos da Aprendizagem do Professor Pesquisador (FAPP). Os dados foram obtidos da observação direta e notas de campo e, também, pelo acesso aos materiais disponibilizados durante o curso. Como resultado principal foi possivel identificar todas as dimensões da aprendizagem do professor pesquisador dentro do contexto desta escola e concluir que tal sujeito encontrava-se numa

\footnotetext{
${ }^{+}$Teacher training at CERN's School of Physics: an analysis based on the Strands of Learning of the TeacherResearcher

* Recebido: 15 de junho de 2020. Aceito: 04 de junho de 2021.

${ }^{1}$ E-mails: thiago.costa@ifpr.edu.br; sergioarruda@uel.br; marinezpassos@uel.br
} 
posição de tríplice aprendiz - da ciência e tecnologia, da docência e da pesquisa.

Palavras-chave: Formação Continuada de Professores de Física; Escola de Física do CERN; Focos da Aprendizagem do Professor Pesquisador.

\begin{abstract}
This article deals with the theme of continuing education for physics teachers, specifically about the so-called CERN School of Physics in 2019, which presents itself as a formative space for Brazilian physics teachers at the European Organization for Nuclear Research (CERN). The Brazilian presence is carried out via a successful partnership with researchers and institutions in Portugal within a training proposal for teachers from Portuguese-speaking countries. In this context, our main theoretical and methodological inspirations for the analysis of this school were: The Strands of Learning of the Teacher Researcher (FAPP) and content analysis. With these assumptions, our main objective was search evidences of learning by a Brazilian participant teacher with the context of FAPP. The data were obtained through direct observation and field notes and through access to the materials made available during the course. As a main result, it was possible to identify practically all dimensions of the learning of the Teacher-Researcher within the context formed by the school and conclude that the teacher researcher is a triple learner, that is, this subject integrates three types of learning: scientifictechnological learning; teacher learning; and research learning; which all develop simultaneously.
\end{abstract}

Keywords: Continuous Education of Physics Teacher; CERN School of Physics; The Strands of Learning of the Teacher Researcher.

\title{
I. Introdução
}

A pesquisa aqui apresentada dedica-se ao tema 'formação de professores de Física', especificamente, aquela que acontece em serviço ou, comumente, chamada de continuada. A importância desse tipo de formação docente é explicitada por Pacca e Villani (2018), quando nos apresentam que: 
A formação permanente ou continuada tem sido particularmente estudada, porque ela poderia trazer frutos imediatos para questões prementes do Ensino Médio atual, por tratar de um profissional já engajado na tarefa de ensinar, usando o que ele já sabe e muitas vezes valendo-se do que aprendeu como aluno ou com professores. (PACCA; VILLANI, 2018, p. 66).

No contexto da presente investigação, em nossa pauta estava o professor de Física diante de uma proposta de formação em serviço, a denominada Escola de Física do Centro Europeu de Pesquisas Nucleares (CERN), realizada anualmente em sua sede na fronteira franco-suíça. Durante um período de aproximadamente dez dias, os professores brasileiros participam de palestras, minicursos e oficinas práticas, com o objetivo de serem multiplicadores desses conhecimentos científicos relacionados à Física Moderna e Contemporânea junto às comunidades escolares em que atuam, com a introdução de tal temática na Educação Básica.

Tal Escola teve início no ano de 2009 para participantes brasileiros, sendo fruto de uma parceria entre pesquisadores e instituições do Brasil e de Portugal e, após uma década, consolida-se como um espaço formativo para professores de Física em serviço (ABREU, 2015). Apresenta-se como momento marcante e motivador aos participantes dessa iniciativa, conforme exposto a seguir.

Em 2014, acompanhei as atividades desenvolvidas ao longo do curso oferecido aos professores [...] tendo vivenciado uma das mais intensas experiências formativas no campo da Física. [...] Para além de um curso de aprofundamento sobre Física de Partículas, é uma experiência única e enriquecedora de sua própria formação profissional e que considera aspectos científicos, acadêmicos, culturais e estéticos. (DA SILVEIRA, 2015, p. 7, grifo nosso).

Ainda no que toca à relação de tal espaço formativo com o fazer docente do professor de Física da Educação Básica, Abreu (2015, p.38, grifo nosso), nos aponta que:

\footnotetext{
[...] professores de origens muito diversas [...] podem assim aprender uns com os outros como vencer os desafios no dia a dia da escola, como tratar assuntos complexos, como lidar com as dificuldades dos seus alunos nas aprendizagens das matérias.
}

Deste modo, esta investigação possui como objetivo principal evidenciar indícios de aprendizagem de um professor brasileiro, participante da edição do ano de 2019 desta Escola de Física, que se propôs a investigar a própria prática no decorrer desta formação continuada, por meio do instrumento denomilnado Focos da Aprendizagem do Professor Pesquisador (FAPP). Os dados que embasam as análises foram obtidos, principalmente, de notas de campo e de relatos do participante, de modo que nos aproximamos de um estudo de caso.

Nas seções seguintes iremos apresentar o contexto desta Escola de forma a delimitar o foco de nossa investigação em torno de aspectos relacionados à aprendizagem docente 
mediante uso de um instrumento que vê o professor como aprendiz da ciência e tecnologia, da docência e da pesquisa em ensino de Ciências.

\section{A Escola de Física do CERN: algumas informações}

O CERN propõe-se a fazer pesquisa fundamental em Física, de forma pública, sem fins militares, consagrando-se ao longo de sua trajetória como um dos grandes empreendimentos científicos da atualidade (GARCIA, 2015).

Associada às investigações básicas acerca do campo das partículas elementares e do modelo padrão da Física, a organização possui como missão "[...] unir pessoas de todo o mundo para expandir as fronteiras da ciência e da tecnologia, para o benefício de todos" (CERN, 2021), de modo que os programas de formação de professores se enquadrem em tais aspectos. Para o caso dos docentes da Educação Básica, a organização mantém programas para professores de Física, tanto em língua inglesa quanto nas línguas maternas dos países que são membros deste Centro (ABREU, 2015). Ao longo de vinte anos de existência, os cursos atingiram cerca de treze mil professores em escala mundial.

Nesse contexto, no ano de 2007, Portugal iniciou a Escola para professores portugueses. Junto a isso, CERN e UNESCO buscaram promover um consórcio com países que ainda não eram membros. No ano de 2009, o Laboratório de Instrumentação e Física Experimental de Partículas (LIP) propôs um projeto-piloto para inserir professores de países não membros dentro do Portuguese Teachers Programme, programa até então específico para os professores portugueses (ABREU, 2015).

$\mathrm{Na}$ busca por inserir mais docentes, no ano de 2009, além dos professores portugueses, participaram brasileiros e moçambicanos, incentivando o surgimento da então denominada Escola de Professores no CERN em Língua Portuguesa. No Brasil, para proporcionar a participação de professores brasileiros, foi criado o programa Escola de Física do CERN, com lançamento de edital anual para seleção dos participantes (GARCIA, 2015).

Desse modo, a participação brasileira desde 2009 se dá, principalmente, mediante a parceria entre pesquisadores e instituições do Brasil e Portugal, por esse ser país membro, favorecendo, além da aquisição dos conhecimentos científicos, uma intensa vivência entre os professores lusófonos, permitindo, por conseguinte, o intercâmbio de experiências e realidades diversas (ABREU, 2015; GARCIA, 2015).

Tais momentos ocorrem, geralmente, após as palestras, nas seções de perguntas e respostas ou revisão do dia, durante os momentos no refeitório do CERN (COUTINHO; PAIVA; BARRELO JUNIOR, 2015) e em atividades culturais na cidade de Genebra.

No que diz respeito ao curso proposto pela Escola, e considerando que ele está há uma década em atividade, a programação possui certa padronização em termos de conteúdos e propostas para os participantes, de modo que podemos separar em três grandes momentos: palestras, visitas e práticas. 
Com certa padronização, nas palestras ocorrem introduções: à Física de Partículas, com ênfase no desenvolvimento do Modelo Padrão das partículas elementares; à estrutura do CERN e suas principais instalações e laboratórios; aos princípios básicos de detecção de partículas; às quatro grandes experiências lá instaladas - ATLAS (A Toroidal LHC Aparatus), CMS (Compact Muon Solenoid), LHCb (Large Hadron Collider beauty), ALICE (A Large Ion Collider Experiment). Cabe destacar que, após confirmação experimental do chamado bóson de Higgs, detalhes de tal feito, assim como os principais detectores envolvidos, podem ser considerados como o foco do curso em Genebra.

As visitas possuem o objetivo de proporcionar a vivência de se conhecer algumas estruturas e laboratórios, aceleradores e, também, detectores do CERN. Nelas tem-se acesso a alguns dos aceleradores lineares, ao centro de controle e, ainda, ao centro de dados, ao local do nascimento da WEB in loco.

Quanto às práticas (ou workshops), as de maior destaque são: a "montagem" e o uso da câmara de nuvens, em que se podem visualizar traços de partículas carregadas, tais como elétrons e/ou partículas alfa interagindo com o vapor de álcool saturado dentro do aparato; a possibilidade de uso de dados reais da experiência ATLAS em um simulador, a fim de seguirmos alguns caminhos possíveis para a descoberta experimental do bóson de Higgs. Em suma, o curso apresenta aos participantes aspectos científicos e tecnológicos associados à Física das partículas elementares, com o intuito de que cada professor, da Educação Básica, atue como multiplicador ao retornar para sua comunidade escolar (ABREU, 2015).

Tais aspectos podem ser observados em diversas publicações relacionadas às Escolas de Física do CERN, que possuem participantes como autores de capítulos de livros (GARCIA, 2015), relatando sobre as experiências vivenciadas ao longo do curso.

Outros participantes de anos anteriores apresentam propostas pedagógicas acerca da inserção da Física Moderna para a Educação Básica (KNEUBIL, 2013; PINHEIRO, 2015). $\mathrm{Na}$ sequência iremos expor o instrumento analítico denominado: Focos da Aprendizagem do Professor Pesquisador (FAPP) em conexão com o contexto da Escola do CERN frente à perspectiva da formação continuada docente.

\section{Os Focos da Aprendizagem do Professor Pesquisador (FAPP)}

A princípio, a aprendizagem docente pode ser abordada a partir do campo da formação de professores e/ou saberes docentes ou pelo tema da aprendizagem em geral. Considerando que o professor - aliás, como todo ser humano - assim que nasce é "[...] submetido à obrigação de aprender" (CHARLOT, 2000, p. 59), nós preferimos tratar o assunto a partir dessa segunda perspectiva.

O professor, portanto, é essencialmente um aprendiz. Mas, o que é aprender? Diversos autores apontam para inúmeras teorias, significados, abordagens e visões sobre a aprendizagem (MOREIRA, 2011; SCHUNK, 2012; WENGER, 2013; ILLERIS, 2013). De um modo geral, temos assumido que a aprendizagem apresenta as seguintes características: 
não pode ser mensurada diretamente, ou seja, é inferencial; seus indícios podem se tornar visíveis por meio de mudanças em uma ou mais variáveis, tais como o comportamento do sujeito, as estruturas cognitivas, as representações, o significado, a realização de tarefas, a própria identidade etc.; tem certa permanência, embora indefinida; é diferente da simples maturação ou o amadurecimento natural do organismo; na maior parte das vezes depende da disposição, envolvimento, interesse ou motivação do sujeito para ocorrer; envolve a participação em comunidades, ou seja, tem uma componente social; e, finalmente, está sempre vinculada a uma ação, uma prática, isto é, ocorre por meio da experiência (BENICIO; ARRUDA; PASSOS, 2020).

No campo da relação com o saber, aprender pode ser: adquirir um saber, um conteúdo intelectual (aprender matemática, o conceito de energia, a teoria da evolução, história da combustão pelo oxigênio etc.); dominar um objeto ou uma atividade (andar, nadar, ler etc.); ou entrar em formas relacionais (cumprimentar uma pessoa, seduzir, mentir etc.). É o que Charlot denomina de "figuras do aprender" (CHARLOT, 2000, p.66). De um modo geral, portanto, aprender pode ser compreendido como uma mudança na relação: com um conteúdo, com um objeto/atividade ou com pessoas.

A aprendizagem, em um primeiro momento, diz respeito, portanto, à aquisição de um conhecimento (conteúdo) específico, mas não só. De fato, adotamos como pressuposto que o processo como um todo também envolve o desenvolvimento de outros aspectos como o interesse, a reflexão, a participação em uma comunidade e a construção de uma identidade. Ou seja, podemos pensar a aprendizagem como tendo cinco dimensões, denominadas de Focos da Aprendizagem, que são: interesse, conhecimento, reflexão, comunidade e identidade, os quais, em geral, são simultaneamente acionados quando uma aprendizagem, em qualquer campo, está em curso (ARRUDA; PORTUGAL; PASSOS, 2018).

Os Focos adquirem nomes específicos de acordo com o campo em que ocorre a aprendizagem: Focos da Aprendizagem Científica (FAC), quando o campo é a Ciência (ARRUDA et al., 2013); Focos da Aprendizagem Docente (FAD), quando o campo é a docência (ARRUDA; PASSOS; FREGOLENTE, 2012); Focos da Aprendizagem para a Pesquisa (FAP), quando o campo envolve a formação de um pesquisador (TEIXEIRA; PASSOS; ARRUDA, 2015). É importante ressaltar que os FAC, FAD e FAP são instrumentos que fornecem indícios de aprendizagem, respectivamente, na ciência, na docência e na pesquisa (ARRUDA; PORTUGAL; PASSOS, 2018).

Recentemente, com base nesses três conjuntos de focos (FAC, FAD e FAP), propusemos uma nova interpretação para o conceito de professor pesquisador. Como é bem conhecida na área de formação de professores, a ideia do professor pesquisador emergiu, na Inglaterra, a partir da década de 60, no contexto das reformas curriculares de algumas escolas secundárias e está relacionada aos nomes de Lawrence Stenhouse e John Elliott (ARRUDA, 2001). 
Stenhouse acreditava que os professores se desenvolveriam mais, como profissionais, se fossem incluídos como participantes em investigações em Educação, concebendo as salas de aula como laboratórios, onde experiências educacionais inovadoras poderiam ser testadas. Stenhouse também considerava que o currículo era o principal meio através do qual as ideias educativas poderiam ser comprovadas e desenvolvidas, e defendia uma visão do currículo como processo, cujo enfoque se dava nos "princípios e valores a serem desenvolvidos", em contraposição do currículo baseado na "racionalidade técnica", que tem como objetivos "[...] especificações precisas sobre os resultados da aprendizagem” (PEREIRA, 1998, p.159).

John Elliott, que foi colaborador de Stenhouse, compara esses dois modelos de currículo à distinção feita por Aristóteles entre poiesis e práxis. Enquanto a primeira se refere a um "[...] conjunto de procedimentos operativos para produzir consequências quantificadas e especificadas previamente", a segunda diz respeito a uma maneira de "[...] atualizar nossos ideais e valores em uma forma adequada de ação" (PEREIRA, 1998, p. 160), requerendo para isso uma contínua reflexão. Portanto, na práxis, a teoria e a prática seriam indissociáveis.

Observando a formação de professores que se envolvem em cursos de pós-graduação (mestrado e doutorado, principalmente) e continuam com suas atividades didáticas, postulamos que tais professores aprendem em três campos distintos (embora interligados): aprendem conceitos científicos (e/ou tecnológicos), aprendem saberes relativos à docência e aprendem a fazer pesquisa, ou seja, professores nessas condições podem desenvolver um triplo aprendizado: da ciência, da docência e da pesquisa (VICENTIN et al., 2020). Se isso pode ser assumido, como poderíamos perceber esse aprendizado? A resposta é: por meio de uma combinação dos FAC, FAD e FAP. A aplicação simultânea desses três conjuntos de focos levou-nos aos Focos da Aprendizagem do Professor Pesquisador, ou FAPP, apresentados no Quadro 1.

Quadro 1 - Focos da aprendizagem do professor pesquisador (FAPP).

\begin{tabular}{|c|c|}
\hline Focos da Aprendizagem do Professor Pesquisador (FAPP) & Subcategorias \\
\hline \multirow{3}{*}{$\begin{array}{l}\text { Foco 1: Interesse [Envolvimento com: o conhecimento científico e } \\
\text { tecnológico; a docência; a pesquisa]. } \\
\text { Descrição: O professor pesquisador experimenta interesse, } \\
\text { envolvimento emocional, curiosidade, motivação, mobilizando-se } \\
\text { para aprender cada vez mais sobre: o conhecimento científico e } \\
\text { tecnológico, a docência e a pesquisa. }\end{array}$} & $\begin{array}{l}1.1 \text { [Envolvimento com o } \\
\text { conhecimento científico e } \\
\text { tecnológico] }\end{array}$ \\
\hline & $\begin{array}{l}1.2 \text { [Envolvimento com a } \\
\text { docência] }\end{array}$ \\
\hline & $\begin{array}{l}1.3 \text { [Envolvimento com a } \\
\text { pesquisa] }\end{array}$ \\
\hline \multirow{3}{*}{$\begin{array}{l}\text { Foco 2: Conhecimento [Conhecimento: científico e tecnológico; dos } \\
\text { referenciais teóricos do tema da pesquisa e dos métodos e técnicas de } \\
\text { coleta e organização de dados; das questões que envolvem a gestão } \\
\text { da sala de aula]. } \\
\text { Descrição: O professor pesquisador demonstra conhecimento } \\
\text { científico e tecnológico e conhecimento relativo à docência e à }\end{array}$} & $\begin{array}{l}2.1 \text { [Conhecimento } \\
\text { científico e tecnológico] }\end{array}$ \\
\hline & $\begin{array}{l}2.2 \text { [Conhecimento relativo } \\
\text { à gestão de sala de aula] }\end{array}$ \\
\hline & $\begin{array}{l}2.3 \text { [Conhecimento relativo } \\
\text { à pesquisa] }\end{array}$ \\
\hline
\end{tabular}




\begin{tabular}{|c|c|}
\hline pesquisa. & \\
\hline \multirow{3}{*}{$\begin{array}{l}\text { Foco 3: Reflexão [Reflete sobre o próprio aprendizado da ciência e } \\
\text { tecnologia, da docência e da pesquisa]. } \\
\text { Descrição: o professor pesquisador demonstra refletir sobre o } \\
\text { conhecimento científico e tecnológico, sobre a docência e sobre a } \\
\text { pesquisa, bem como o seu aprendizado nesses três campos. }\end{array}$} & $\begin{array}{l}3.1 \text { [Reflexão sobre o } \\
\text { próprio aprendizado da } \\
\text { ciência e tecnologia] }\end{array}$ \\
\hline & $\begin{array}{l}3.2 \text { [Reflexão sobre sua } \\
\text { prática docente e seu } \\
\text { aprendizado da docência] }\end{array}$ \\
\hline & $\begin{array}{l}3.3 \text { [Reflexão sobre o } \\
\text { próprio aprendizado da } \\
\text { pesquisa] }\end{array}$ \\
\hline \multirow{3}{*}{$\begin{array}{l}\text { Foco 4: Comunidade [Envolvimento com a prática de comunidade } \\
\text { científica e docente]. } \\
\text { Descrição: O professor pesquisador está inserido em comunidades } \\
\text { científicas, docentes e de pesquisa, aprendendo sobre as práticas e a } \\
\text { linguagem da ciência, da docência e da pesquisa com outros } \\
\text { cientistas, docentes e pesquisadores, assimilando valores dessas } \\
\text { comunidades e desenvolvendo reflexões coletivas nesses três campos. }\end{array}$} & $\begin{array}{l}4.1 \text { [Envolvimento e } \\
\text { aprendizado com a } \\
\text { comunidade científico- } \\
\text {-tecnológica] }\end{array}$ \\
\hline & $\begin{array}{l}4.2 \text { [Envolvimento e } \\
\text { aprendizado com a } \\
\text { comunidade docente] }\end{array}$ \\
\hline & $\begin{array}{l}4.3 \text { [Envolvimento e } \\
\text { aprendizado com a } \\
\text { comunidade de pesquisa] }\end{array}$ \\
\hline \multirow{3}{*}{$\begin{array}{l}\text { Foco 5: Identidade ou identificação com a ciência e tecnologia, com a } \\
\text { docência e a pesquisa [Visão de si mesmo como: aprendiz da ciência } \\
\text { e tecnologia, docente e pesquisador]. } \\
\text { Descrição: O professor pensa sobre si mesmo como: aprendiz da } \\
\text { ciência e tecnologia, docente e pesquisador. }\end{array}$} & $\begin{array}{l}5.1 \text { [Visão de si mesmo } \\
\text { como aprendiz da ciência e } \\
\text { tecnologia] }\end{array}$ \\
\hline & $\begin{array}{l}5.2 \text { [Visão de si mesmo } \\
\text { como docente] }\end{array}$ \\
\hline & $\begin{array}{l}5.3 \text { [Visão de si mesmo } \\
\text { como pesquisador] }\end{array}$ \\
\hline
\end{tabular}

Fonte: Adaptado de Vicentin et al. (2020) e Arruda, Portugal e Passos (2018)

Os FAPP foram aplicados a dados provenientes de relatos de um professor que estava estudando a utilização da lousa digital em suas aulas. Ao mesmo tempo, este professor também atuava como pesquisador, estando envolvido com a elaboração de sua dissertação de mestrado. Por meio dessa investigação "[...] foi possível observar evidências de aprendizagem do professor pesquisador em todos os eixos que compõem os FAPP" (VICENTIN et al., 2020 , p. 54). Constatou-se que o professor integrou, simultaneamente, três tipos de aprendizagem:

[...] a aprendizagem cientifica/tecnológica que aconteceu por conta de estar aprendendo a utilizar um equipamento novo, no caso da lousa digital; a aprendizagem docente que acabou ocorrendo devido ao planejamento e execução das aulas e da preocupação do professor com a aprendizagem, em matemática, dos estudantes por meio desse recurso tecnológico; a aprendizagem da pesquisa devido 
à sua inserção em um grupo de pesquisa e em um programa de pós-graduação que intensificou sua participação em eventos cientificos, culminando com o desenvolvimento de uma pesquisa (VICENTIN et al., 2020, p.75).

$\mathrm{Na}$ sequência, apresentamos a descrição do contexto da pesquisa e os procedimentos metodológicos empregados na coleta e análise dos dados expostos como resultados nesta investigação.

\section{Descrições sobre a pesquisa e seus procedimentos metodológicos}

Nosso ambiente de pesquisa foi a edição do ano de 2019 da Escola de Física do CERN, de modo que os dados utilizados nesta investigação, cujos resultados interpretativos trazemos neste artigo, são provenientes de notas de campo e de relatos de um único sujeito, brasileiro, professor de Física da Educação Básica, aluno de doutorado e participante da referida edição do curso, e foi assumido como professor pesquisador, no sentido que demos a essa concepção na seção anterior.

Essas disposições levaram-nos a caracterizar a investigação como de cunho qualitativo e interpretativo, pois como descrevem Bogdan e Biklen (1994), tal modalidade pode ser caracterizada por cinco descritores: a fonte de dados é o ambiente natural, sendo o investigador o principal instrumento; a investigação é descritiva; o interesse da pesquisa se dá mais em torno do processo do que apenas dos resultados e/ou produtos; a análise dos dados segue uma tendência indutiva; o significado é de importância vital.

Isso nos remete ao ocorrido, em que o ambiente natural da Escola foi fonte de dados primários utilizados para a exposição das informações e interpretação analítica, tendo por inspiração os FAPP como categorias a priori.

Além desses marcos teórico e metodológico, trouxemos o posicionamento do observador participante, amparado pelo que nos apresentam Lüdke e André (2001, p.27):

O "observador como participante" é um papel em que a identidade do pesquisador e os objetivos do estudo são revelados ao grupo pesquisado desde o início. Nessa posição, o pesquisador pode ter acesso a uma gama variada de informações, até mesmo confidenciais, pedindo cooperação ao grupo. Contudo, terá em geral que aceitar o controle do grupo sobre o que será ou não tornado público pela pesquisa (grifo das autoras).

Nesse sentido, juntamente com a observação participante, aproximamo-nos do delineamento de um estudo de caso, pois ainda, de acordo com Flick (2009, p.135), "[...] o objetivo de um estudo de caso é a descrição exata ou reconstrução de um caso". De modo que:

O termo "caso" deve ser entendido aqui de uma forma bastante ampla. Pode-se adotar, como tema de uma análise de caso, pessoas, comunidades sociais (por 
exemplo, famílias), organizações e instituições (por exemplo, uma casa de repouso). O problema principal, então, será identificar um caso significativo para a questão de pesquisa e esclarecer o que mais compete a esse caso e "quais abordagens metodológicas são necessárias à sua reconstrução”. (FLICK, 2009, p.135, grifos nossos).

No que diz respeito à organização e análise dos dados, empregamos os procedimentos da Análise de Conteúdo (AC), em que se designa sob esse termo um

[...] conjunto de técnicas de análise das comunicações visando obter, por
procedimentos sistemáticos e objetivos de descrição do conteúdo das mensagens,
indicadores (quantitativos ou não) que permitam a inferência de conhecimentos
relativos às condições de produção/recepção (variáveis inferidas) dessas
mensagens. (BARDIN, 2016, p.48).

Em nossa compreensão, é uma técnica que nos permite construir um metatexto com conclusões a partir da organização e da categorização de um determinado conjunto de documentos (BARDIN, 2016). Por isso assumimos, como indicado anteriormente, em nossas análises, os FAPP (em suas cinco dimensões) por categorias a priori.

Cabe informar que para o movimento interpretativo realizado seguimos algumas etapas: 1. Preparação do material; 2. Unitarização; 3. Categorização. 4. Descrição; 5. Interpretação, tendo sempre como elemento de observação, os registros do caderno de campo realizados durante os seis dias de participação no curso, as ações relatadas e as interações realizadas pelo próprio professor investigado, sujeito da pesquisa ou Professor Pesquisador (PP).

Os registros diários foram executados pelo próprio $\mathrm{PP}$, a respeito da sua participação em cada um dos dias de curso, sendo então codificados como $\mathrm{NC}_{1, \mathrm{~A}}$ (trecho $\mathrm{A}$ da nota de campo do primeiro dia de curso), sendo que o primeiro índice varia de 1 a 6 (total máximo de dia da realização do curso) e o segundo índice varia de A até Z (última letra do nosso alfabeto). Outros materiais complementares também foram acessados e empregados, a fim de compor os registros das notas de campo, como aqueles disponibilizados pelos palestrantes e que se encontram no sítio do evento.

De posse de todos esses registros passamos a unitarizá-los e a acomodá-los em cada um dos cinco Focos preestabelecidos, movimento esse que permitiu, posteriormente, a evidenciação de subcategorias que serão apresentadas e descritas na próxima seção.

\section{Indícios de aprendizagem para um PP}

Apresentamos nos quadros a seguir fragmentos de trechos dos relatos e registros realizados pelo PP, alocados em subcategorias (listadas no Quadro 1), a fim de evidenciar indícios de aprendizagem na proposta de formação continuada de que ele participou. 
Quadro 2 - Foco 1 (Interesse) e suas subcategorias.

\begin{tabular}{|c|c|}
\hline Subcategorias & Exemplos $^{2}$ de fragmentos analisados \\
\hline $\begin{array}{l}1.1 \\
\text { [Envolvimento } \\
\text { com o } \\
\text { conhecimento } \\
\text { científico e } \\
\text { tecnológico] }\end{array}$ & $\begin{array}{l}\mathrm{NC}_{3, \mathrm{C}}-\mathrm{Eu} \text { quero muito fazer essa câmara de nuvens, que foi apresentada em } \\
\text { uma das oficinas do curso, [...] estou muito empolgado para construí-la, preciso } \\
\text { ou achar gelo seco ou ver outro jeito [...] talvez aquelas pastilhas Peltier que } \\
\text { "esfriam" de um lado e "aquecem" do outro ou mesmo tentar com compressor } \\
\text { para "baixar" a temperatura. Eu já tinha pensado em fazê-la há alguns anos, mas } \\
\text { na época achei muito complicado, mas agora esse interesse reapareceu e ficou } \\
\text { mais forte porque se conseguir baixar a temperatura não precisa usar nenhuma } \\
\text { outra fonte "radioativa", as próprias partículas que conseguem atravessar a } \\
\text { atmosfera e chegar até a superfície. É muito bacana ver os traços deixados na } \\
\text { câmara de nuvens. }\end{array}$ \\
\hline $\begin{array}{l}1.2 \\
\text { [Envolvimento } \\
\text { com a docência] }\end{array}$ & $\begin{array}{l}\mathrm{NC}_{1, \mathrm{~A}} \text { - Começando o curso aqui na Suíça, estou muito empolgado com as } \\
\text { possibilidades de usar os materiais, ideias para aplicar tanto no Ensino Médio e } \\
\text { superior, além de buscar conectar os alunos lá do interior com o CERN. Em } \\
\text { geral, estou bem motivado para atuar como disseminador. Sei que está } \\
\text { começando, mas este curso já está me motivando a me aprimorar e me envolver } \\
\text { cada vez mais com a profissão de ensinar Física. }\end{array}$ \\
\hline $\begin{array}{l}1.3 \\
\text { [Envolvimento } \\
\text { com a pesquisa] }\end{array}$ & $\begin{array}{l}\mathrm{NC}_{1, \mathrm{C}}-\text { Nossa }[\ldots] \text { olhando para esse curso [...] estou com expectativas boas } \\
\text { também para conseguir integrar ao meu projeto de doutorado, ainda não sei qual } \\
\text { caminho a seguir, mas fiquei empolgado ao ver que tem um livro produzido e } \\
\text { artigos publicados a partir das experiências de alguns professores participantes } \\
\text { de anos anteriores, também tenho muita vontade de publicar alguma coisa a } \\
\text { partir desta experiência aqui em conexão com a minha pesquisa em ensino de } \\
\text { Ciências. }\end{array}$ \\
\hline
\end{tabular}

Fonte: Os autores.

As ações referentes às subcategorias relativas ao Foco Interesse, apresentadas no Quadro 2, nos indicam que o PP experimentou envolvimento emocional, curiosidade e, principalmente, motivação ao se envolver com os detalhes, características e conceitos científicos relacionados a um aparato experimental, a chamada câmara de nuvens, sentindo então necessidade de construí-la.

Por sua vez, o mesmo sente-se novamente motivado a empregar os conhecimentos a serem apreendidos durante a Escola do CERN com seus alunos, sente-se ainda envolvido na função de multiplicador e divulgador de tais saberes e, também, de forma mais geral é possível inferir que houve um reforço em seu envolvimento com a docência de Física. Em relação à pesquisa, sobretudo pelas buscas por publicações dentro da área de ensino de Ciências relacionadas ao curso na Suíça, PP demonstrou empolgação e motivação pela conexão entre sua futura tese e a participação no evento.

\footnotetext{
${ }^{2}$ Apresentamos somente exemplos de fragmentos das anotações de observações, pensamentos e reflexões do Professor Pesquisador (PP), sujeito da pesquisa, pois a completude dos dados tornaria o artigo muito extenso.
} 
Deste modo, procuramos explicitar, nesta categoria, principalmente, o envolvimento do PP para aprender mais sobre o conhecimento científico e tecnológico; sobre a docência e a pesquisa, apresentando assim um interesse triplo. No Quadro 3, apresentamos a categoria Conhecimento e as subcategorias identificadas que evidenciaram a aprendizagem do PP quanto ao conhecimento científico e tecnológico, relativo à gestão de sala de aula e à pesquisa.

Quadro 3 - Foco 2 (Conhecimento) e suas subcategorias.

\begin{tabular}{|c|c|}
\hline Subcategorias & Exemplos de fragmentos analisados \\
\hline $\begin{array}{l}2.1 \\
\text { [Conhecimento } \\
\text { científico e } \\
\text { tecnológico] }\end{array}$ & $\begin{array}{l}\mathrm{NC}_{2, \text { в }} \text { - Hoje, na visita ao setor que o pessoal informalmente chama de } \\
\text { "fábrica de antimatéria"3, aprendemos sobre a produção de um átomo de } \\
\text { antimatéria, o anti-hidrogênio, que é composto por um pósitron ou antielétron } \\
\text { e por um antipróton, ou seja, tem a mesma massa do próton só que com carga } \\
\text { negativa. E ainda eles fazem a espectroscopia para buscar alguma diferença } \\
\text { entre matéria e antimatéria, mas até agora o resultado disto só vai } \\
\text { comprovando que há simetria entre a matéria e antimatéria. }\end{array}$ \\
\hline $\begin{array}{l}2.2 \\
\text { [Conhecimento } \\
\text { relativo à gestão } \\
\text { de sala de aula] }\end{array}$ & $\begin{array}{l}\mathrm{NC}_{2} \text {, D - Esse filme, apresentado aos participantes na Suíça, "A febre das } \\
\text { partículas", é muito interessante para "passar" aos alunos, pena que não será } \\
\text { disponibilizado devido aos direitos autorais. Mas, vão passar outro filme } \\
\text { introdutório chamado "Descobrindo o CERN", que também será útil para } \\
\text { despertar o interesse sobre o tema nos alunos, de maneira a introduzir a } \\
\text { temática da Física de partículas de forma gradual, principalmente no Ensino } \\
\text { Médio. }\end{array}$ \\
\hline $\begin{array}{l}2.3 \\
\text { [Conhecimento } \\
\text { relativo à } \\
\text { pesquisa] }\end{array}$ & $\begin{array}{l}\mathrm{NC}_{5,} \text { A - Com essa palestra sobre o "Impacto das Escolas do CERN para } \\
\text { professores no Brasil e em Portugal" eu consigo dados junto a coordenadores, } \\
\text { como possíveis elementos para minha tese. Falei com o palestrante hoje que } \\
\text { estava querendo trabalhar com a noção de redes. Ele achou interessante, me } \\
\text { passou algumas dicas, disponibilizou a apresentação e mais dados dos anos } \\
\text { anteriores caso eu precise. Me questionou sobre como estava fazendo a coleta } \\
\text { de dados. Respondi que estava fazendo notas de campo, gravações das } \\
\text { palestras, oficinas, que havia realizado levantamento dos artigos relacionados à } \\
\text { pesquisa em ensino de Ciências e às escolas do CERN, e que iria investigar } \\
\text { aprendizagem docente ou mesmo discente lá no meu contexto de trabalho. }\end{array}$ \\
\hline
\end{tabular}

Fonte: Os autores.

Evidenciamos, a partir do Quadro 3, algumas atividades executadas por PP que denotam a busca pela aprendizagem teórica e prática do conhecimento científico e tecnológico, sobretudo ao empregar a linguagem científica, a fim de aprofundar sua

\footnotetext{
${ }^{3}$ Antimatter Factory.
} 
compreensão a respeito do fenômeno relacionado à "produção" de antimatéria em um dos setores do CERN. A subcategoria que diz respeito à gestão de sala de aula (2.2) indica ações de planejamento por parte do PP, para que possa ter êxito no processo de ensino e aprendizagem científica, especificamente, pela introdução de conceitos relacionados à Física de partículas, respeitando assim os conhecimentos dos alunos na escolha pela introdução gradual de tais conteúdos, partindo inicialmente pelo uso de um instrumento audiovisual, ou seja, o filme.

Com relação à subcategoria - Conhecimento relativo à pesquisa -, o excerto apresentado indica evidência do aprendizado relacionado à coleta de dados para sua pesquisa e uma prévia organização e leitura de artigos, com o intuito de compor um referencial teórico. Portanto, para este Foco 2 (Conhecimento) evidencia-se a aprendizagem deste sujeito de pesquisa, pois ele demonstra: conhecimento científico e tecnológico, sobretudo, conceitual; conhecimento relativo à pesquisa e, ainda, aquele que envolve a prática da docência. No Quadro 4, trazemos a categoria Reflexão e as subcategorias evidenciadas, além de fragmentos representativos dos registros para o PP.

Quadro 4 - Foco 3 (Reflexão) e suas subcategorias.

\begin{tabular}{|c|c|}
\hline Subcategorias & Exemplos de fragmentos analisados \\
\hline $\begin{array}{l}3.1 \text { [Reflexão } \\
\text { sobre o próprio } \\
\text { aprendizado da } \\
\text { ciência e } \\
\text { tecnologia] }\end{array}$ & $\begin{array}{l}\mathrm{NC}_{2} \text {, A - No setor de manutenção SM-18, eu fiquei impressionado com o } \\
\text { desenvolvimento dessa liga metálica que suporta uma intensidade de corrente de } \\
\text { até } 13.000 \mathrm{~A} \text { em uma dimensão tão reduzida. Foi possível ver também outros } \\
\text { detalhes dos materiais envolvidos na construção dos criodipolos, como a } \\
\text { construção dos tubos, de forma a fazer com que os feixes fiquem sempre } \\
\text { posicionados no centro desses dispositivos, o material empregado que auxilia a } \\
\text { fazer o vácuo dentro destes tubos ao capturar as partículas do ar que ainda } \\
\text { restam no interior; Aprendi bastante a respeito então dos materiais e técnicas } \\
\text { envolvidas em alguns detalhes dos tubos onde "passam" os feixes de partículas. }\end{array}$ \\
\hline $\begin{array}{l}3.2 \text { [Reflexão } \\
\text { sobre sua } \\
\text { prática docente } \\
\text { e seu } \\
\text { aprendizado da } \\
\text { docência] }\end{array}$ & $\begin{array}{l}\mathrm{NC}_{1, \mathrm{D}} \text { - Esta palestra sobre princípios básicos de detecção, especificamente essa } \\
\text { primeira parte sobre Erros e Incertezas, achei muito interessante para trabalhar } \\
\text { junto à minha disciplina de Epistemologia da Ciência com a licenciatura em } \\
\text { Física, sobre a relação entre a teoria e experimento vou conseguir apresentar a } \\
\text { eles usando o exemplo da detecção do bóson de Higgs. Tenho que ressaltar } \\
\text { também nas disciplinas de laboratório, a importância dos erros experimentais. } \\
\mathrm{NC}_{2, \mathrm{C}}-\mathrm{Eu} \text { gostaria muito de tentar fazer as visitas virtuais no ATLAS e CMS } \\
\text { (detectores). Esse último é mais interessante para os alunos porque um } \\
\text { pesquisador desce até a caverna do detector e mostra ele de perto. Mas, } \\
\text { infelizmente, para a licenciatura não será possível fazer devido ao fuso horário } \\
\text { com a Europa [...] vou tentar unir várias turmas do Ensino Médio para realizar } \\
\text { essas visitas nos detectores. } \\
\text { NC } C_{5, \mathrm{C}}-\mathrm{Eu} \text { quero fazer essas simulações, sobre eventos de colisões, com os } \\
\text { alunos, mas acredito que não será possível fazer junto com o Ensino Médio. } \\
\text { Acho meio complexo para eles [...] embora em Portugal o pessoal dos últimos }\end{array}$ \\
\hline
\end{tabular}




\begin{tabular}{|c|c|}
\hline & $\begin{array}{l}\text { anos da educação básica faça, mas conhecendo nossa realidade vou trabalhar } \\
\text { com a licenciatura em Física, só que tenho ainda que fazer uma introdução } \\
\text { sobre a Física de partículas antes de eles entrarem na simulação diretamente. } \\
\text { Provavelmente vou adaptar e tenho que estudar melhor porque ainda fiquei com } \\
\text { dúvidas e são muitos detalhes. }\end{array}$ \\
\hline $\begin{array}{l}3.3 \text { [Reflexão } \\
\text { sobre o próprio } \\
\text { aprendizado da } \\
\text { pesquisa] }\end{array}$ & $\begin{array}{l}\mathrm{NC}_{1, \mathrm{D}} \text { - Não sei se vou conseguir usar todos os dados aqui do curso para } \\
\text { compor o corpus da minha pesquisa, mas acredito que seja melhor já me } \\
\text { preparar e por isso vou aproveitar e fazer notas de campo, uns relatos, e depois } \\
\text { também vou aproveitar a gravação de áudio das palestras para obter o máximo } \\
\text { de dados possíveis para um dos caminhos possíveis para a tese. } \\
\mathrm{NC}_{3} \text {, D - Acredito que alguns daqueles instrumentos desenvolvidos por alguns } \\
\text { pesquisadores do grupo de pesquisa Educim } 4 \text {, relacionados aos indícios de } \\
\text { aprendizagem docente, possam ser aproveitados por mim, talvez os FAD ou } \\
\text { talvez os FAPP, porque percebo que vários dos professores participantes são } \\
\text { alunos de mestrado ou doutorado em ensino de Ciências; ou focar nos FAC dos } \\
\text { alunos. } \\
\mathrm{NC}_{5} \text {, D - Refletindo a partir da oficina de hoje sobre uso de simulações das } \\
\text { colisões no ATLAS ou CMS, acho que seria interessante conectar a minha } \\
\text { prática com os estudantes da licenciatura em Física com minha pesquisa de } \\
\text { doutorado, talvez ao longo da disciplina de laboratório de Física Moderna, } \\
\text { desenvolver uma sequência didática e avaliar aspectos das ações discentes ou } \\
\text { conexão entre minha ação docente e ações discentes ou ainda naquela área } \\
\text { relacionada à Teoria Ator-Rede, evidenciar de alguma maneira a influência dos } \\
\text { softwares nas ações dos estudantes. }\end{array}$ \\
\hline
\end{tabular}

Fonte: Os autores.

A partir do excerto apresentado para a subcategoria - Reflexão sobre o próprio aprendizado científico e tecnológico - tem-se a indicação de reflexões que levaram o PP a compreender elementos da conexão entre ciência e tecnologia, especificamente, neste caso, na relação entre o tipo de liga metálica empregada em tal situação, a fim de suportar um valor extremo para a corrente elétrica necessária para permitir o movimento circular dos prótons dentro do tubo do LHC (Large Hadrions Collider), assim como nas especificidades dos materiais e técnicas empregadas, a fim de manter o vácuo no interior dos tubos.

A análise da subcategoria (3.2) permitiu-nos inferir que, em diversos momentos, tal professor, embasado em instrumentos teóricos e, principalmente, em sua experiência prática, analisou as situações e, dentro de um processo constante sobre sua própria prática, planejou ações que o permitirão resolver, implementar ou aprimorar elementos em sua prática pedagógica.

Na continuidade, ao examinarmos a subcategoria (3.3) foi possível constatar que, frente aos possíveis problemas investigativos originados da interação do pesquisador com sua

${ }^{4}$ EDUCIM - Grupo de Pesquisa em Educação em Ciências e Matemática. Que pode ser conhecido em: $<$ http://educim.com.br/>. 
prática docente, tanto no seu local de trabalho quanto na Escola do CERN e, ainda, embasado por alguns elementos teóricos, ele analisa as situações envolvendo-se, portanto, com a pesquisa e a reflexão do processo.

Por fim, tais análises permitiram evidenciar para tal contexto a constante reflexão do PP sobre sua própria aprendizagem científica e tecnológica, sua prática docente e sua atuação na pesquisa, de modo que diante de tal processo reflexivo temos momentos em que sobressai o professor e, em outros, o pesquisador, em uma constante interação.

Na sequência, expomos, no Quadro 5, o Foco Comunidade e as subcategorias evidenciadas para a aprendizagem do PP nas comunidades: científica e tecnológica; docente; de pesquisa.

Quadro 5 - Foco 4 (Comunidade) e suas subcategorias.

\begin{tabular}{|l|l|}
\hline Subcategorias & Exemplos de fragmentos analisados \\
\hline $\mathrm{NC}_{2, \mathrm{~F}}-\mathrm{Na}$ visita ao setor de manutenção $\mathrm{SM}-18$, um dos palestrantes que \\
era engenheiro eletrônico nos acompanhou e nos mostrou e foi \\
comentando sobre vários detalhes a respeito de várias peças empregadas \\
nos criodipolos 5 , que compõem o anel do LHC. Nos apresentou e \\
explicou sobre as ligas metálicas desenvolvidas para suportar 13.000A de \\
corrente, por exemplo, explicou os pormenores cada componente e sua \\
função no criodipolo, apresentou também o processo de descida das partes \\
até o túnel do LHC, comentou sobre as obras de engenharia civil e sua \\
complexidade. \\
$\begin{array}{l}\text { NC } 1 \text { [Envolvimento e Achei muito interessante na palestra "Introdução à Física de } \\
\text { aprendizado com a } \\
\text { comunidade } \\
\text { científico- } \\
\text {-tecnológica] }\end{array}$
\end{tabular}

${ }^{5} \mathrm{O}$ criodipolo pode ser considerado como uma parte individual de $15 \mathrm{~m}$ de comprimento, que conectados entre si formam a estrutura do anel do LHC. 


\begin{tabular}{|l|l|}
\hline $\mathrm{NC}_{6, \mathrm{E}}-$ Hoje é o último dia de curso e visualizei muitas possibilidades de \\
integrar esse curso aqui dentro do meu projeto de doutorado, já coletei \\
alguns dados, organizei alguns artigos, mas ainda não sei direito qual \\
caminho seguir. Se eu vou buscar analisar os docentes ou tentar ver mais \\
especificamente lá na minha realidade local do câmpus. No retorno eu \\
vou apresentar no Educim do doutorado e tenho certeza que vou sair com \\
um caminho de lá. No grupo sempre o meu orientador, os professores e os \\
colegas contribuem com o caminhar da nossa pesquisa.
\end{tabular}

Fonte: Os autores.

Os excertos apresentados no Quadro 5, relacionados com aspectos da aprendizagem com a comunidade científica e tecnológica para PP, são exemplos representativos de parte de todo o curso oferecido pela Escola do CERN, pois várias das palestras e oficinas foram ministradas por pesquisadores e engenheiros portugueses, de modo que durante o período de formação ele teve contato com os saberes apresentados por membros desta comunidade científica e tecnológica presente e envolvida com a operação e pesquisa realizada no LHC.

A análise da subcategoria - Envolvimento e aprendizado com a comunidade docente -, revelou um exemplar, em que o PP recebeu diversas sugestões e instruções por parte de outros professores com mais experiência e (ou) que já realizaram com sucesso a montagem do aparato experimental - a câmara de nuvens.

Por sua vez, a subcategoria (4.3) explicita aprendizagens mediadas pelo grupo de pesquisa, comunidade da qual PP (como estudante de doutorado) faz parte, com a intenção de ser chancelado como doutor e pesquisador. Tal participação leva-o a um processo de aprendizagem a respeito das práticas e linguagem da pesquisa, assimilando assim valores e reflexões coletivas junto aos demais participantes desta comunidade.

Finalizamos, evidenciando nesta categoria as comunidades em que PP mostra-se inserido, destacando seu envolvimento e aprendizado.

Na sequência, expomos o Quadro 6, com a categoria Identidade e as subcategorias que evidenciam a visão de si como aprendiz da ciência e tecnologia, como docente e como pesquisador.

Quadro 6 - Foco 5 (Identidade) e suas subcategorias.

\begin{tabular}{|l|l|}
\hline Subcategorias & Exemplos de fragmentos analisados \\
\hline $\begin{array}{l}5.1 \text { [Visão de si } \\
\text { mesmo como } \\
\text { aprendiz da } \\
\text { ciência e } \\
\text { tecnologia] }\end{array}$ & $\begin{array}{l}\mathrm{NC}_{6, \mathrm{C}}-\mathrm{A} \text { partir deste curso, penso até em voltar para a universidade para fazer } \\
\text { algumas disciplinas específicas sobre Física de partículas ou modelo padrão, de } \\
\text { maneira geral, me aprofundar mais no aprendizado da linguagem matemática } \\
\text { envolvida. Percebi também que passei a buscar e ler mais as reportagens } \\
\text { relacionadas à Física de partículas e a ciência básica também de forma ampla e } \\
\text { continuada desde quando fui selecionado para vir para este curso. }\end{array}$ \\
\hline
\end{tabular}




\begin{tabular}{|l|l|}
\hline $\begin{array}{l}\text { 5.2 [Visão de si } \\
\text { mesmo como } \\
\text { docente] }\end{array}$ & $\begin{array}{l}\mathrm{NC}_{6, \mathrm{D}} \text { - Esse curso também me motivou a implementar a Física de partículas na } \\
\text { minha prática docente, principalmente buscando isso com experimentos. Mas, } \\
\text { de forma geral, esse curso me deu mais segurança para abordar esta temática, } \\
\text { tanto com os alunos quanto para outros professores. No retorno, vou até propor } \\
\text { uma disciplina optativa sobre Física de partículas na licenciatura em Física. }\end{array}$ \\
\hline & $\begin{array}{l}\mathrm{NC}_{3, \mathrm{~B}} \text { - Estou gostando de fazer este doutorado na área de ensino de Ciências, } \\
\text { porque não é necessário já ter definido o problema logo no início, pois ao longo } \\
\text { do caminhar, possíveis problemas de pesquisa vão surgindo como esta conexão } \\
\text { entre minha realidade de trabalho com essa Escola do CERN. Sinto uma } \\
\text { identificação maior agora com a área da pesquisa em ensino do que no início do } \\
\text { doutorado, porque agora as leituras, os métodos de análises passaram a fazer } \\
\text { sentido, de certo modo passei a olhar este curso também pelo viés da pesquisa, } \\
\text { pensando na melhor forma de coletar dados, de quem poderia entrevistar após } \\
\text { mesmo como de squisador] curso, o referencial teórico-metodológico mais adequado para este } \\
\text { este } \\
\text { contexto. }\end{array}$ \\
\hline
\end{tabular}

Fonte: Os autores.

Embasados nos excertos selecionados para serem inseridos no Quadro 6, para a subcategoria (5.1) fica perceptível o sentimento de pertencimento do PP, quando relata que passou a buscar e ler mais reportagens científicas relacionadas ao tema do curso na Suíça, assim como pelo desejo apresentado de continuar a se dedicar ao estudo da temática.

Para a subcategoria relativa ao Foco 5 (Identidade) - Visão de si mesmo como docente -, foi possível perceber evidências de identificação do PP como docente ao pensar sobre si mesmo como aprendiz da docência na busca por tornar-se um profissional melhor com a inserção de atividades experimentais, pela motivação em oferecer uma nova disciplina diante da sua realidade de trabalho na licenciatura.

Para a subcategoria (5.3), foi possível evidenciar pelo relato apresentado, e que é representativo de outros tantos que não trouxemos no quadro, um aumento na identificação com a área de pesquisa por parte do PP e aliada à aquisição do léxico presente no programa de doutoramento de que faz parte - Programa de Pós-Graduação em Ensino de Ciências e Educação Matemática (PECEM) da Universidade Estadual de Londrina (UEL). Inferimos, portanto, que PP desenvolveu uma tripla identidade, na interface de ver a si mesmo como aprendiz de ciência e tecnologia, como docente e como pesquisador.

Fatos esses que nos remetem ao que apresenta Abreu (2015), quando indica que não se pretende com estas Escolas dar uma formação para a pesquisa em Física básica aos participantes, mas sim motivá-los a falar em suas aulas sobre o CERN, a Física Moderna e como funciona a ciência global. Deste modo, tal apontamento aproxima-nos do fato do PP assumir sua realidade como campo de pesquisa, especificamente, em ensino de Física, percebendo a conexão entre o ser professor de Física e ser um futuro pesquisador em Ensino de Ciências e Educação Matemática (quando for diplomado). 
A inserção deste professor em um ambiente de doutoramento e, principalmente, como participante de um grupo de pesquisa permite a denominação de tal sujeito de pesquisa como professor pesquisador neste contexto, pois se verificou evidências de aprendizado relacionado à elaboração de projeto de pesquisa; levantamento de referencial bibliográfico; coleta e tratamento de dados; aquisição de conhecimento relacionado à metodologia de pesquisa. O que nos leva a afirmar que, para este contexto, evidenciamos indícios de um tríplice aprendizado: o científico e tecnológico; da docência e da pesquisa permeados pelo contexto formativo da Escola de Física do CERN.

\section{Considerações finais}

Neste artigo apresentamos os resultados de uma investigação que tratou da formação docente proporcionada pela participação de um professor na Escola de Física do CERN no ano de 2019. Mais especificamente, analisamos indícios de aprendizagem da ciência e tecnologia, da docência e da pesquisa por meio de um instrumento denominado Focos da Aprendizagem do Professor Pesquisador (FAPP).

Constatou-se, diante da análise dos dados, que o sujeito da pesquisa desenvolveu uma tripla aprendizagem, pois no corpus investigativo foram encontrados elementos que indicavam o Interesse, o Conhecimento, a Reflexão, a inserção na Comunidade e a Visão sobre si (Identidade) como cientista e técnico, como docente e como pesquisador, o que nos remete ao conceito de desenvolvimento profissional do professor.

Embora este conceito não seja univocamente definido na literatura, ele pode ser entendido como um processo que melhora o conhecimento e as competências dos professores, apresentando, dentre outras, as seguintes características: pode significar "uma atitude permanente de pesquisa, de questionamento e busca de soluções", que "tem como finalidade última melhorar a aprendizagem dos alunos"; usualmente ocorre no contexto de uma instituição ou organização, envolvendo colaboração entre professores e tem a ver com a "mudança de atitude" dos mesmos; inclui o desenvolvimento pedagógico, da compreensão de si mesmo, cognitivo, teórico e o desenvolvimento na carreira (GARCIA, 1999, p.137-138). Ou seja, de um modo geral, podemos concluir que a participação do professor na referida Escola contribuiu para o seu desenvolvimento profissional.

\section{Referências}

ABREU, P. A Escola de Física em Língua Portuguesa. In: GARCIA, N. M. D. (Org.). Nós professores brasileiros de Física do Ensino Médio estivemos no CERN. São Paulo: Livraria da Física, 2015. p. 37-58.

ARRUDA, S. M. Entre a inércia e a busca: reflexões sobre a formação em serviço de professores de Física do ensino médio. 2001. 238 f. Tese (Doutorado em Educação) - 
Faculdade de Educação, USP, São Paulo, 2001. Disponível em <https://www.teses.usp.br/ teses/disponiveis/48/48133/tde-05032002-132057/publico/TDE.pdf>. Acesso em: 23 fev. 2021.

ARRUDA, S. M.; PASSOS, M. M.; FREGOLENTE, A. Focos da aprendizagem docente. Alexandria, Florianópolis, v. 5, n. 3, p. 25-48, 2012. Disponível em: $<$ https://periodicos.ufsc.br/index.php/alexandria/article/view/37734/29158>. Acesso em: 10 jun. 2020.

ARRUDA, S. M.; PASSOS, M. M.; PIZA, C. A. de M.; FELIX, R. A. B. O aprendizado científico no cotidiano. Ciência \& Educação, Bauru, v. 19, n. 2, p. 481-498, 2013. Disponível em: <http://www.redalyc.org/articulo.oa?id=251027945016>. Acesso em: 12 out. 2019.

ARRUDA, S. M.; PORTUGAL, K. O.; PASSOS, M. M. Focos da aprendizagem: revisão, desdobramentos e perspectivas futuras. REPPE: Revista de Produtos Educacionais e Pesquisas em Ensino, Cornélio Procópio, v. 2, n. 1, p. 91-121, 2018. Disponível em: $<$ http://seer.uenp.edu.br/index.php/reppe/article/view/1298>. Acesso em: 18 jan. 2021.

BARDIN, L. Análise de conteúdo. Tradução: Luís Antero Reto e Augusto Pinheiro. São Paulo: Edições 70, 2016.

BENICIO, M. A.; ARRUDA, S. M.; PASSOS, M. M. Um estudo quantitativo das conexões entre a ação docente e a ação discente em aulas de Matemática, Física e Química em um Instituto Federal do Paraná. Contexto \& Educação, Ijuí, v. 35, n. 112, p. 456-477, 2020. Disponível em: $<$ https://www.revistas.unijui.edu.br/index.php/contextoeducacao/ article/view/ 9127>. Acesso em: 10 jun. 2020.

BOGDAN, R.; BIKLEN, S. Investigação Qualitativa em Educação. Tradução: Maria João Alvarez e Sara Bahia dos Santos. Portugal: Porto Editora, 1994.

CERN. home.cern, 2021. Nossa missão. Disponível em: <https://home.cern/about/who-weare/our-mission>. Acesso em: 18 jan. 2021.

CHARLOT, B. Da relação com o saber: elementos para uma teoria. Porto Alegre: Artmed, 2000.

COUTINHO, A. C. L. F.; PAIVA, J. R.; BARRELO JUNIOR, N. Comunicação Visual na Escola de Física do CERN. In: GARCIA, N. M. D. (Org.). Nós professores brasileiros de 
Física do Ensino Médio estivemos no CERN. São Paulo: Livraria da Física, 2015. p. 303-318 .

DA SILVEIRA, H. E. Prefácio. In: GARCIA, N. M. D. (Org.). Nós professores brasileiros de Física do Ensino Médio estivemos no CERN. São Paulo: Livraria da Física, 2015.

FLICK, U. Introdução à Pesquisa Qualitativa. Tradução: Joice Elias Costa. Porto Alegre: Artmed, 2009.

GARCIA, C. M. Formação de professores: para uma mudança educativa. Porto: Porto Editora, 1999.

GARCIA, N. M. D. Apresentação. In: GARCIA, N. M. D. (Org.). Nós professores brasileiros de Física do Ensino Médio estivemos no CERN. São Paulo: Livraria da Física, 2015.

ILLERIS, K. Uma compreensão abrangente sobre a aprendizagem humana. In: ILLERIS, K. (Org.). Teorias contemporâneas da aprendizagem. Porto Alegre: Penso, 2013. p. 15-30.

KNEUBIL, F. B. Explorando o CERN na física do Ensino Médio. Revista Brasileira de Ensino de Física, São Paulo, v. 35, n. 2, p. 2401-1-2401-10, 2013. Disponível em: $<$ https://www.scielo.br/pdf/rbef/v35n2/21.pdf>. Acesso em: 18 jan. 2021.

LÜDKE, M.; ANDRÉ, M. E. D. A. Pesquisa em Educação: abordagens qualitativas. São Paulo: E.P.U., 2001.

MOREIRA, M. A. Teorias da Aprendizagem: cognitivismo, humanismo e comportamentalismo. São Paulo: E.P.U., 2011.

PACCA, J. J. A.; VILLANI, A. A formação continuada do professor de Física. Estudos Avançados, São Paulo, v. 32, n. 94, p. 57-71, 2018. Disponível em: $<$ https://www.scielo.br/pdf/ea/v32n94/0103-4014-ea-32-94-00057.pdf >. Acesso em: 18 jan. 2021.

PEREIRA, E. M. A. Professor como pesquisador: o enfoque da pesquisa-ação na prática docente. In: GERALDI, C. M. G.; FIORENTINI, D.; PEREIRA, E. M. A. (Org.). Cartografias do Trabalho Docente. Campinas: Mercado das Letras, 1998. 
PINHEIRO, L. S. A câmara de nuvens: uma abordagem integrada entre a Física Clássica e a Física Moderna. Caderno Brasileiro de Ensino de Física, Florianópolis, v. 32, n. 2, p. 517 -528, 2015. Disponível em: <https://periodicos.ufsc.br/index.php/fisica/article/view/21757941.2015v32n2p517>. Acesso em: 18 jan. 2021.

SCHUNK, D. H. Learning theories: an educational perspective. Boston: Pearson Education, 2012.

TEIXEIRA, L. A.; PASSOS, M. M.; ARRUDA, S. M. A formação de pesquisadores em um grupo de pesquisa em Educação em Ciências e Matemática. Ciência \& Educação, Bauru, v. 21, n. 2, p. 525-541, 2015. Disponível em: <http://www.scielo.br/pdf/ciedu/v21n2/1516-7313ciedu-21-02-0525.pdf $>$. Acesso em: 18 jan. 2021.

VICENTIN, F. R.; PASSOS, M. M.; ARRUDA, S. M.; PASSOS, A. M. Focos da Aprendizagem do Professor Pesquisador. Revista Brasileira de Ensino de Ciência e Tecnologia, Ponta Grossa, v. 13, n. 1, p. 54-78, 2020. Disponível em: $<$ https://periodicos.utfpr.edu.br/rbect/article/view/8869>. Acesso em: 19 jun. 2020.

WENGER, E. Uma teoria social da aprendizagem. In: ILLERIS, K. (Org.). Teorias contemporâneas da aprendizagem. Porto Alegre: Penso, 2013. p. 246-257. 